diminution in basic character of the ammonia nitrogen. All the chlorophyll derivatives examined contain at least one and possibly two of the very weakly basic groups $(a)$ or $(b)$ :

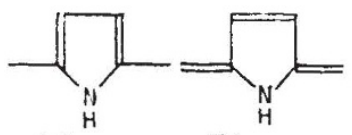

(a) (b)

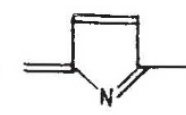

(c)

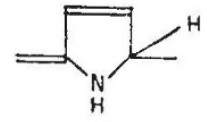

(d) pyrrole isopyrrole pyrrolenine hydropyrrole

and they gave $p K_{3}^{1}$ values of $-1 \cdot 9$ to $-2 \cdot 4$.

With very few exceptions, all these compounds also contain one rather strongly basic group with a $p K_{1}^{1}$ value of $+1 \cdot 8$ to $+2 \cdot 3$, which, as titrations of two methenes indicated, was probably the oxidised pyrrole or pyrrolenine ring (c), having one $\alpha, \beta$. unsaturated linkage and a tertiary nitrogen atom. Pyridine has also a $p K^{1}$ value of $+2 \cdot 93$, which is the lower limit of basic strength in the glacial acetic acid system. This system gives satisfactory results for basic strengths of compounds such as urea, which have $p K$ in water of about zero, and compounds so weakly basic (for example, acetanilide and acetamide) that they cannot be measured in water.

The porphyrins stand out as a group from all other chlorophyll derivatives in containing two relatively strong basic groups, of average $p K^{1}$ of $+2 \cdot 5$. The chlorins are differentiated from the porphyrins in having only one relatively strongly basic group, with $p K^{1}=+2 \cdot 1$, and one group intermediate in basicity between the pyrrole and pyrrolenine groups, possibly an oxidation or reduction product of the latter in which the character of the nitrogen atom is changed. The basicity of this group is influenced by substituent groups and is comparable with the basicity of urea and acetoxime. This result leads to a correction of a previous formula for chlorin $f$, which is now supposed to contain a hydropyrrole nucleus $(d)$ in place of one of the two pyrrolenine rings previously assumed by Conant.

The true chlorophyll-a compounds, the phæophorbides, are found to contain one relatively strongly basic and one very weakly basic group, as in the chlorins. The intermediate group, however, is less basic than in the chlorins; but whether this difference is significant of a radically different structure is difficult to say. In the $b$ series, rhodin- $l$ is the simplest compound and corresponds with chlorin $f$ in the $a$ series. The two basic groups in rhodin- $l$ are weaker than in the $a$ series, but rhodin- $g$ is very similar to chlorin-e. Methyl phæophorbide- $b$ is markedly different from the $a$ compound in the relatively strongly basic group. It appears that the extra oxygen atom in the $b$ series affects the basicity of all the compounds, which would be unlikely if it were in the side chain of the propionic acid group, as postulated by Fischer.

The interpretation of the results of the new potentiometric titration experiments is still incomplete and rather tentative; but it is clear that the method promises to throw light on the structure of compounds containing basic groups, and its extension from the chlorophylls and porphyrins into other fields is obvious.

${ }^{1}$ Summarised in R. Willstätter and A. Stoll, "Untersuchungen über Chlorophyll", Berlin, 1913.

Pedler Lecture, $J$. Chem. Soc., 245 ; 1934

${ }^{3}$ Many papers in $\dot{J}$. Amer. Chem. Soc., 1929 to date.

4 Critical summary of the literature by K. F. Armstrong, Chemistry and Industry, 809; 1933.

${ }^{5}$ E. M. Dietz and T. H. Werner, $J$. Amer. Chem. Soc., 56, 2180 1934.

${ }^{6}$ J. B. Conant, B. F. Chow and E. M. Dietz, J. Amer. Chem. Soc. 56, 2185; 1934.

${ }^{7}$ J. B.'Conant and T. H. Werner, J. Amer. Chem. Soc., 52, 4436 ; 1930 ; J. B. Conant and B. F. Chow, ibid., 55, 3745; 1933.

\title{
Fuel Research in Great Britain*
}

$\mathrm{T}$ HE work of the Fuel Research Board touches many aspects of the technology of fuel, and the annual report for the year ending March 1934 therefore provides a useful review of the problems before the coal and other fuel industries.

In the first place, the report emphasises the steady accumulation of information by the survey of the coalfields of Great Britain, the value of which becomes increasingly evident as the demands on the properties of fuel become more exacting.

Reference is made to the fall in demand for large lump coal in recent years. Formerly, collieries made great efforts to avoid breaking coal because the consumer was prepared to pay, for size, a premium which was disproportionate to the calorific value of the coal itself. Actually the consumer paid his premium for a fuel the cleanness of which was visible to the eye. Now more than 77 million tons of coal is washed and its quality can be guaranteed, irrespective of size. Industrial fuel is nearly always wanted in small pieces, especially when firing is automatic. The modern house has little room for storage, and the householder wishes to avoid the trouble and dirt of breaking coal. One can foresee a time when the large lumps will become unsaleable,

* Department of Scientific and Industrial Research. Report of the Fuel Research Board for the Year ended 31st March 1934, with Report of the Director of Fuel Research. Pp. vii +178. (London: H.M. Stationery Office, 1934.) 38. net. and already some collieries are seeking the best and most efficient manner of breaking down lump coal without the undue formation of dust. Many difficult problems arise when coals are broken, such as the best treatment of wash water containing dust, and the staff of the Fuel Research Board is engaged on their examination.

A section of the report deals with the liquid fuels from coal. A small fraction of the needs of Great Britain is covered by the by-products of coal carbonisation, that is, benzole and coal tar oils. Most of the liquid fuel is imported from distant parts where Nature has provided a bounteous though, from our point of view, ill-placed supply of oil. The geographical distribution of petroleum provides food for speculation as to what the distribution of man might have been had he known of the existence of the oil earlier, or had understood how to obtain, control and distribute the natural gas which accompanies oil in such abundance. Industries might have been very differently situated, and it is improbable that men would have toiled against the hazards of coal-getting if such an ideal fuel as methane were available without effort. Even as it is, Governments all over the world are exerting themselves to turn solid into liquid fuels by processes which are technically speaking heroic but, judged by ordinary standards, uneconomic. The studies of the Fuel 
Research Board on this problem are interesting because so much of the experience in this field is in private hands.

It is shown that a large proportion of coal tarsindeed practically the whole of a low temperature tar-can be hydrogenated to first-class motor spirit, and a larger plant for this purpose is being erected. As regards the hydrogenation of coal itself, the influence of minor inorganic ingredients is receiving special attention. Lubricants are not less important than the fuels and it is found that although some are obtainable from coal products, they are not yet suitable for common use.

Considerable attention is being given to the use of pulverised fuel at sea. The 'grid' burner for pulverised fuel devised at the Fuel Research Station is now in commercial use. Favourable reports are received of the use of pulverised fuel with this burner, and it is claimed to be, in general operation, equal to oil firing in similar furnaces, but more economical both thermally and in cost.

A new feature is the appointment of a 'scientific panel' of academic chemists, who are to engage upon more academic investigation bearing on fuel processes. The Board is also giving financial support, but unfortunately on a scale reduced in 1931, to other investigations in university laboratories. H. J. H.

\section{University and Educational Intelligence}

Cambridan.--R. I. N. Greaves, of Clare College, has been appointed University demonstrator in pathology. Dr. J.D. Boyd, of the Queen's University, Belfast, and R. S. Handley, of Gonville and Caius College, have been appointed University demon. strators in anatomy.

The University Catholic Societies in Great Britain, twenty-three in number, are federated in an organisation which is linked with other national student federations through "Pax Romana", an international secretariat to which papal recognition was, for the first time, formally accorded last April. The British federation has marked its sense of the importance of this event by publishing in its Year Book for 1934-35 somewhat detailed expositions of its aims and policy and those of Pax Romana, and a report on a pilgrimage to Rome of a party of 130 of its members. Its general aim is to assist in the "Catholic education of persons of academic standing", the process being developed pari passu with secular studies and comprising, in addition to religious exercises, Catholic philosophy, Catholic social principles, Catholic missionary efforts and Catholic "action in the world at large". Further light on its outlook is to be found in the report, published in the Year Book, of the proceedings of its annual meeting held at Edinburgh on June 29-July 2, 1934. Here the general theme of the discussions was "The Catholic Approach to Knowledge", the chief contributions being papers read by Prof. G. Temple of King's College, London, on "Man and Knowledge" in which the supreme importance of metaphysics was urged, by Prof. E. T. Whittaker on "Man and the Universe" and by Mr. J. A. Lauwerys, of the University of London Institute of Education, on "Man and Life", in which he stresses, as in his book on "Education and Biology", a vitalistic point of view and the importance of teleology.

\section{Science News a Century Ago}

\section{Social Economics}

On February 16, 1835, a paper by Lieut.-Col. Sykes was read to the Statistical Society ontitled "On the Increase of Wealth and Expenditure in the Various Classes of Society, as indicated by the Returns made to the Tax Office, by Exports, Imports, and Savings Banks". The classes included in this review were the gentry, the trading and manufacturing bodies and the depositors in savings banks, and the author gave some interesting particulars regarding the increase of capital employed in various articles of trade and luxury. The increase in popula. tion of England, from 1821 to 1831, he said, had been $11 \cdot 3$ per cent (from $11,760,555$ to $13,091,005$ ) and for the entire population of Great Britain and Ireland the increase had been somewhat more, from $21,726,924$ to $24,306,719$. In the same period, the poor rates had risen from $£ 6,674,083$ to $£ 8,316,617$. The total number of depositors in the savings banks was 475,155 and the amount deposited $£ 15,715,111$. In concluding his paper, Col. Sykes said it had been his object to offer a practical illustration of the facilities the Statistical Society afforded to everyone to collate facts with the view of showing the actual state and past changes in the condition of society.

\section{Civil List Pensions for Men of Science}

The recognition by the Government a century ago of eminent men of science led in the first place to the conferment of several knighthoods. It was next resolved to grant Civil List pensions. The first of these was awarded to Airy, then thirty-four years of age. On February 17, 1835, Sir Robert Peel wrote to Airy and in the course of his letter he said : "I consider you to have the first claim on the Royal Favour which Eminence in those high Pursuits to which your life is devoted, can give, and I fear that the Emoluments attached to your appointment in the University of Cambridge are hardly sufficient to relieve you from anxiety as to the Future on account of those in whose welfare you are deeply interested."

"The state of the Civil List would enable me to advise the King to grant a pension of three hundred pounds per annum, and if the offer be acceptable to you the Pension shall be granted either to Mrs. Airy or yourself as you may prefer."

"I beg you distinetly to understand that your acquiescence in this Proposal, will impose upon you no obligation personal or political in the slightest degree. ...."

Airy replied from the Observatory, Cambridge, on the following day, thanking Sir Robert Peel, and asking that the pension might be settled on Mrs. Airy. Peel replied on February 19, saying: "I will give immediate directions for the preparation of the warrant settling the Pension on Mrs. Airy. . . . I assure you I never gave an official order which was accompanied with more satisfaction to myself than this."

\section{Wheatstone on Musical Sounds}

At King's College, London, on February 17, 1835, Wheatstone delivered an introductory lecture on musical sounds. A report of the lecture appeared in the Athenaeum of February 21, 1835. After showing how the oscillations of bells and string and wind instruments could be made visible, Wheatstone went on 